УДК 624.04

\title{
УЧЕТ ПОЛЗУЧЕСТИ И УСАДКИ БЕТОНА ПО СП 5.03.01-2020 ПРИ РАСЧЕТЕ ЖЕЛЕЗОБЕТОННЫХ КОНСТРУКЦИЙ НА ОСНОВЕ ДЕФОРМАЦИОННОЙ РАСЧЕТНОЙ МОДЕЛИ
}

\author{
Д. Н. Лазовский ${ }^{1}$, В. В. Тур ${ }^{2}$, Д. О. Глухов ${ }^{3}$, Е. Д. Лазовский \\ ${ }^{1}$ Д. т. н., профессор, профрессор кафредры строительных конструкций учреждения образования \\ «Полоцкий государственный университет», Новополоцк, Беларусь, e-mail: d.lazovski@psu.by \\ ${ }^{2}$ Д. т. н., профессор, заведующий кафедрой технологии бетона и строительных материалов учреждения образования \\ «Брестский государственный технический университет», Брест, Беларусь, e-mail: tur.s320@mail.ru \\ ${ }^{3}$ K. т. н., доцент, доцент кафредры вычислительных систем и сетей учреждения образования \\ «Полоцкий государственный университет», Новополоцк, Беларусь, e-mail: d.gluhov@psu.by \\ ${ }^{4}$ K. m. н., доцент, заведующий кафредрой строительных конструкций учреждения образования \\ «Полоцкий государственньй университет», Новополоцк, Беларусь, e-mail: y.lazouski@psu.by
}

\section{Реферат}

Свойства усадки и ползучести бетона характеризуются способностью деформироваться с течением времени без приращения внешних нагрузок. Данные свойства бетона оказывают влияние на напряженно-деформированное состояние железобетонных элементов. В зависимости от вида железобетонной конструкции (балки, колонны) отличается и влияние усадки и ползучести на напряженно-деформированное состояние.

В статье приводятся результаты анализа напряженно-деформированного состояния нормальных сечений железобетонных элементов с учетом деформаций усадки и ползучести бетона на основе деформационной расчетной модели, применимой для вычисления параметров трещинообразования и деформаций железобетонных элементов при произвольной форме и компоновке поперечного сечения, любом расположении арматуры в пределах сечения.

Ключевые слова: усадка бетона, ползучесть бетона, железобетон, десормационная модель расчета, трещиностойкость.

\section{CREEP AND SHRINKING OF CONCRETE ACCOUNTING ACCORDING TO SP 5.03.01-2020 WHEN ANALYSIS OF REINFORCED CONCRETE STRUCTURES BASED ON DEFORMATIONAL ANALYTICAL MODEL}

\section{Abstract}

\section{N. Lazouski, V. V. Tur, D. O. Gluhov, Y. D. Lazouski}

The shrinkage and creep properties of concrete are characterized by the ability to deform over time without changing of external loads. These concrete properties affect the stress-strain state of reinforced concrete elements. Depending on the type of reinforced concrete structure (beams, columns), the effect of shrinkage and creep on the stress-strain state is also different.

The article presents the results of the analysis of the stress-strain state of normal sections of reinforced concrete elements, taking into account shrinkage and creep deformations of concrete, based on a deformation design model, applicable to analyze the parameters of deformations and cracking of reinforced concrete elements with an arbitrary shape of the cross section, any arrangement of reinforcement within the section.

Keywords: shrinkage of concrete, creep of concrete, reinforced concrete, deformation design model, crack resistance.

\section{Введение}

Усадка и ползучесть - свойства бетона, существенно влияющие на напряженно-деформированное состояние железобетонных конструкций $[1,2,3]$. Деформации усадки и ползучести бетона развиваются во времени. Арматура железобетонной конструкции вследствие ее сцепления с бетоном становится внутренней связью, сдерживающей развитие этих десормаций, и источником возникающих в ней дополнительных усилий и дополнительных напряжений в бетоне. Воздействие усадки при твердении бетона всегда вызывает деформации его укорочения, а ползучесть бетона во времени вызывает при действии растягивающих напряжений - деформации удлинения, а при действии сжимающих напряжений - деформации укорочения.

В зависимости от вида силового воздействия (сжатие, растяжение, изгиб) различно влияние усадки и ползучести бетона на напряженно-деформированное состояние железобетонных конструкций. В сжатых железобетонных элементах бетон, уменьшаясь в объеме от действия усадки и укорачиваясь от влияния ползучести, вызывает напряжения сжатия в арматуре, а арматура, сопротивляясь сжатию, вызывает растягивающие напряжения в бетоне. В растянутых элементах деформация усадки бетона уменьшает напряжения в арматуре и увеличивает напряжения в бетоне, а действие ползучести бетона обратно действию усадки. В изгибаемых с несимметричным армированием элементах, как правило, деформации ползучести бетона вызывают напряженно-деформированное состояние, аналогичное действию внешней нагрузки, а деформации усадки бетона состояние обратное действию внешней нагрузки.

По своей природе усадка и ползучесть бетона связана с его структурой, процессами твердения цементного камня, капиллярными явлениями. При твердении бетона, а также при действии нагрузки во времени происходит перераспределение усилий с текучей гелевой структуры на кристаллические сростки и зерна заполнителя, происходит перемещение избыточной воды в капиллярах и микропорах.

В принятом Министерством архитектуры и строительства Республики Беларусь нормативном документе СП 5.03.01-2020 «Бетонные и железобетонные конструкции» [4] указывается, что в общем случае расчета при произвольной форме и компоновке сечения, любом расположении арматуры в пределах сечения, расчетное сопротивление железобетонной конструкции определяют с использованием деформационной расчетной модели. Аналогично выполняется расчет относительных деформаций и напряжений при определении ширины раскрытия трещин и кривизны и изгибной жесткости. При этом следует учитывать вынужденные деформации (например, при усадке или действии температуры, а также ползучести). Кроме того, значительную долю потерь напряжения в предварительно напряженной арматуре составляют потери от усадки и ползучести бетона. 


\section{Учет деформаций усадки бетона}

В нормальном сечении статически определимого бетонного элемента в результате действия усадки напряжений на возникает. В нормальном сечении аналогичного железобетонного элемента усадка бетона сдерживается арматурой, в результате чего и в арматуре, и в бетоне возникают усилия, которые находятся в равновесии.

Согласно [4] относительную деформацию полной усадки $\varepsilon_{c s}\left(t, t_{s}\right)$ бетона в момент времени $t$, имеющего возраст $t_{s}$ к моменту начала воздушно-сухого хранения, определяют по формуле

$$
\varepsilon_{c s}\left(t, t_{s}\right)=\varepsilon_{c b s}(t)+\varepsilon_{c d s}\left(t, t_{s}\right),
$$

где $\varepsilon_{c b s}(t)$ - относительная десормация базовой усадки бетона, зависящая от прочности бетона, вида и класса прочности цемента;

$\varepsilon_{c d s}\left(t, t_{s}\right)$ - относительная деформация усадки высыхания бетона, учитывающая вид цемента и влияние относительной влажности среды хранения.

Определение параметров напряженно-десрормированного состояния железобетонных элементов при действии нагрузки с учетом усадки бетона производится в два этапа. На первом этапе рассматривается незагруженный внешней нагрузкой элемент. Определяются параметры напряженно-десрормированного состояния при воздействии деформаций усадки бетона, которые будут являться начальными на втором этапе расчета.

При действии усадочных деформаций в арматуре возникают деформации сжатия, а в бетоне - деформации растяжения. При несимметричном армировании железобетонного элемента на поле напряжений от усадки бетона накладывается дополнительно поле вторичных напряжений от внецентренного приложения усилий в бетоне относительно центра тяжести арматуры сечения, что эквивалентно действию изгибающего момента. Таким образом, на первом этапе рассматривается состоящий из арматурных стержней элемент, для которого справедлива гипотеза плоских сечений, и на который действует внецентренно приложенное сжимающее усилие от усадки бетона. В результате расчета в момент времени $t$ определяются относительные деформации в стержнях арматуры, а также дополнительные относительные десормации элементарных площадок бетона (рис. 1).

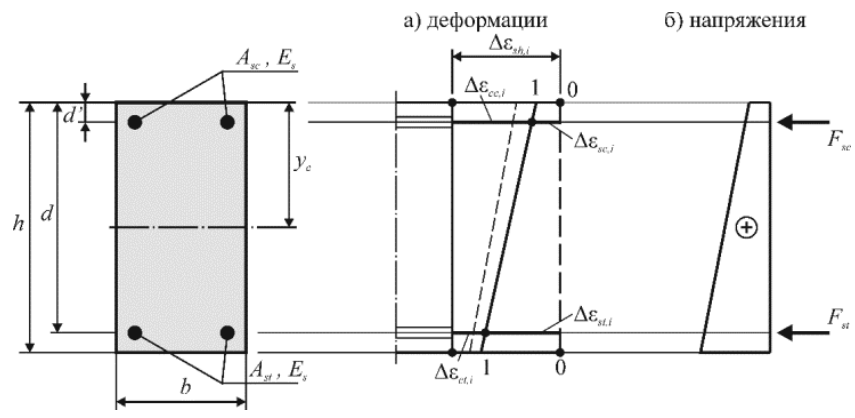

Рисунок 1 - К определению распределения относительных деформаций в сечении

В общем случае для условий связанной (несвободной) усадки приращение относительной деформации во времени следует определять из условия совместности деформаций:

$$
\left(\Delta \varepsilon_{c}\right)_{i}=\left(\Delta \sigma_{c}\right)_{i} I\left(t_{i+1 / 2} ; t_{i}\right)+\sum_{j=1}^{i-1}\left[\left(\Delta \sigma_{c}\right) ; \Delta I\left(t_{i} ; t_{j}\right)\right]+\left(\Delta \varepsilon_{s h}\right)_{i},(2)
$$

где $\Delta /\left(t_{i} ; t_{j}\right)=\frac{\varphi\left(t_{i+1 / 2} ; t_{j}\right)-\varphi\left(t_{(i-1)+1 / 2} ; t_{j}\right)}{E_{c, 28}}$ определяется как функция сопротивления.

Деформации бетона на верхней (сжатой) и нижней (растянутой при нагружении) фрибрах бетона на уровне арматурных стержней получают из решения следующих уравнений:

$$
\begin{aligned}
& \Delta \varepsilon_{c c, i}=\Delta \sigma_{c c, i} I\left(t_{i+1 / 2} ; t_{i}\right)+\sum_{j=1}^{i-1} \Delta \sigma_{c c, j} \Delta I\left(t_{i} ; t_{j}\right)+\Delta \varepsilon_{s h, i}, \\
& \Delta \varepsilon_{c t, i}=\Delta \sigma_{c t, i} I\left(t_{i+1 / 2} ; t_{i}\right)+\sum_{j=1}^{i-1} \Delta \sigma_{c t, j} \Delta I\left(t_{i} ; t_{j}\right)+\Delta \varepsilon_{s h, i},
\end{aligned}
$$

где $\varepsilon_{c c, i}$ - приращение относительных деформаций бетона на уровне верхних стержней для $i$-го временного интервала;

$\varepsilon_{c t, i}-$ приращение относительных деформаций бетона на уровне арматуры в растянутой зоне для $i$-го временного интервала;

$\sigma_{c c, i}, \sigma_{c t, i}-$ приращение напряжений для того же временного интервала в бетоне на уровне верхней и нижней арматуры соответственно;

$\Delta \varepsilon_{s h, i}-$ приращение деформаций свободной усадки.

Принимая допущение о линейном распределении относительных деформаций по высоте сечения и вводя обозначения:

$$
\begin{aligned}
& \left\{\begin{array}{l}
\alpha_{c c}=\frac{A_{s c} E_{s}}{A_{c}}\left(1+\frac{\left(d^{\prime}-y_{c}\right)^{2}}{l_{c} / A_{c}}\right) ; \\
\alpha_{t t}=\frac{A_{s t} E_{s}}{A_{c}}\left(1+\frac{\left(d-y_{c}\right)^{2}}{l_{c} / A_{c}}\right) ; \\
\alpha_{t c}=\frac{A_{s t} E_{s}}{A_{c}}\left(1+\frac{\left(d-y_{c}\right)\left(d^{\prime}-y_{c}\right)}{l_{c} / A_{c}}\right) ; \\
\alpha_{c t}=\frac{A_{s c} E_{s}}{A_{c}}\left(1+\frac{\left(d-y_{c}\right)\left(d^{\prime}-y_{c}\right)}{l_{c} / A_{c}}\right) . \\
\Delta \sigma_{c c, i}=-\alpha_{c c} \cdot \Delta \varepsilon_{s c, i}-\alpha_{t c} \cdot \Delta \varepsilon_{s t, i},
\end{array}\right. \\
& \Delta \varepsilon_{c t, i}=-\alpha_{c t} \cdot \Delta \varepsilon_{s c, i}-\alpha_{t t} \cdot \Delta \varepsilon_{s t, i} .
\end{aligned}
$$

Получаем в матричной форме:

$$
\begin{aligned}
& {\left[\begin{array}{cc}
1+\alpha_{c c} I\left(t_{i+1 / 2} ; t_{i}\right) & \alpha_{t c} I\left(t_{i+1 / 2} ; t_{i}\right) \\
\alpha_{c t} I\left(t_{i+1 / 2} ; t_{i}\right) & 1+\alpha_{t t} I\left(t_{i+1 / 2} ; t_{i}\right)
\end{array}\right]\left\{\begin{array}{c}
\Delta \varepsilon_{s c, i} \\
\Delta \varepsilon_{s t, i}
\end{array}\right\}=} \\
& =\sum_{j=1}^{i-1}\left\{\begin{array}{l}
\Delta \sigma_{c c, j} \Delta I\left(t_{i} ; t_{j}\right) \\
\Delta \sigma_{c t, j} \Delta I\left(t_{i} ; t_{j}\right)
\end{array}\right\}+\left\{\begin{array}{l}
\Delta \varepsilon_{s h i} \\
\Delta \varepsilon_{s h i}
\end{array}\right\} .
\end{aligned}
$$

Из решения уравнений (6) получают распределение относительных деформаций в сечении и значения усилий в арматурных стержнях. Далее выполняют расчет напряжений в бетоне из условий равновесия.

Система уравнений в двух плоскостях, состоящая из уравнений равновесия и условия совместности деформаций, описывающего положение плоскости распределения деформаций по сечению, на первом этапе расчета имеет вид:

$$
\left\{\begin{array}{l}
\iint \sigma(\varepsilon(x, y))\left(y-y_{o}\right) d x d y=0 \\
\iint \sigma(\varepsilon(x, y))\left(x-x_{o}\right) d x d y=0 \\
\iint \sigma(\varepsilon(x, y)) d x d y=0 \\
\varepsilon(x, y)=\varepsilon_{z}-\frac{1}{r_{x}}\left(x-x_{0}\right)-\frac{1}{r_{y}}\left(y-y_{0}\right)+\varepsilon_{c s}\left(t, t_{s}\right)
\end{array},\right.
$$

где $\sigma(x, y)$ - нормальные напряжения в точке с координатами $(x, y)$ бетона или арматуры;

$\varepsilon(x, y)$ - относительная деформация от действия усадки в точке $(x, y)$ бетона или арматуры;

$x_{0}$ и $y_{0}$ - координаты центра тяжести сечения; 
$\frac{1}{r_{x}}$ и $\frac{1}{r_{y}}-$ кривизна продольной оси элемента относительно соответственно оси $x$ и $y$;

$\varepsilon_{c s}\left(t, t_{s}\right)$ - относительная деформация от действия полной усадки бетона в момент времени $t$, имеющего возраст $t_{s}$ к началу воздушно-сухого хранения;

$\varepsilon_{z}$ - относительная деформация от действия усилия усадки бетона, соответствующая его центральному приложению.

Решая систему уравнений равновесия (7) нелинейной деформационной модели, мы вводим деформацию усадки бетона в уравнения совместности деформаций. Расчет выполняется до равновесного состояния по напряжениям относительно центра тяжести сечения. При этом необходимо отметить, что критерии остановки итерационного процесса по продольной силе и изгибающему моменту принимаются на несколько порядков меньше, чем для расчета при силовом воздействии, поскольку речь идет о поиске равновесия при малых значениях внутренних усилий.

В результате расчета определяются параметры напряженнодеформированного состояния железобетонного элемента в его поперечном сечении, нормальном к его продольной оси, в результате воздействия усадочных напряжений. Полученные на первом этапе расчета параметры напряженно-деформированного состояния железобетонного элемента будут являться начальными при последующем нагружении конструкции.

Для примера рассматривается поперечное сечение железобетонного элемента 500 × 250 мм из обычного бетона класса $\mathrm{C}^{25} / 30$ с симметричным и несимметричным армированием четырьмя стержнями $\varnothing 20$ (Ø12) мм класса $S 500, \varepsilon_{c s}\left(t, t_{s}\right)=0,00025$.

Результаты расчета представлены на рис. 2 и рис. 3.
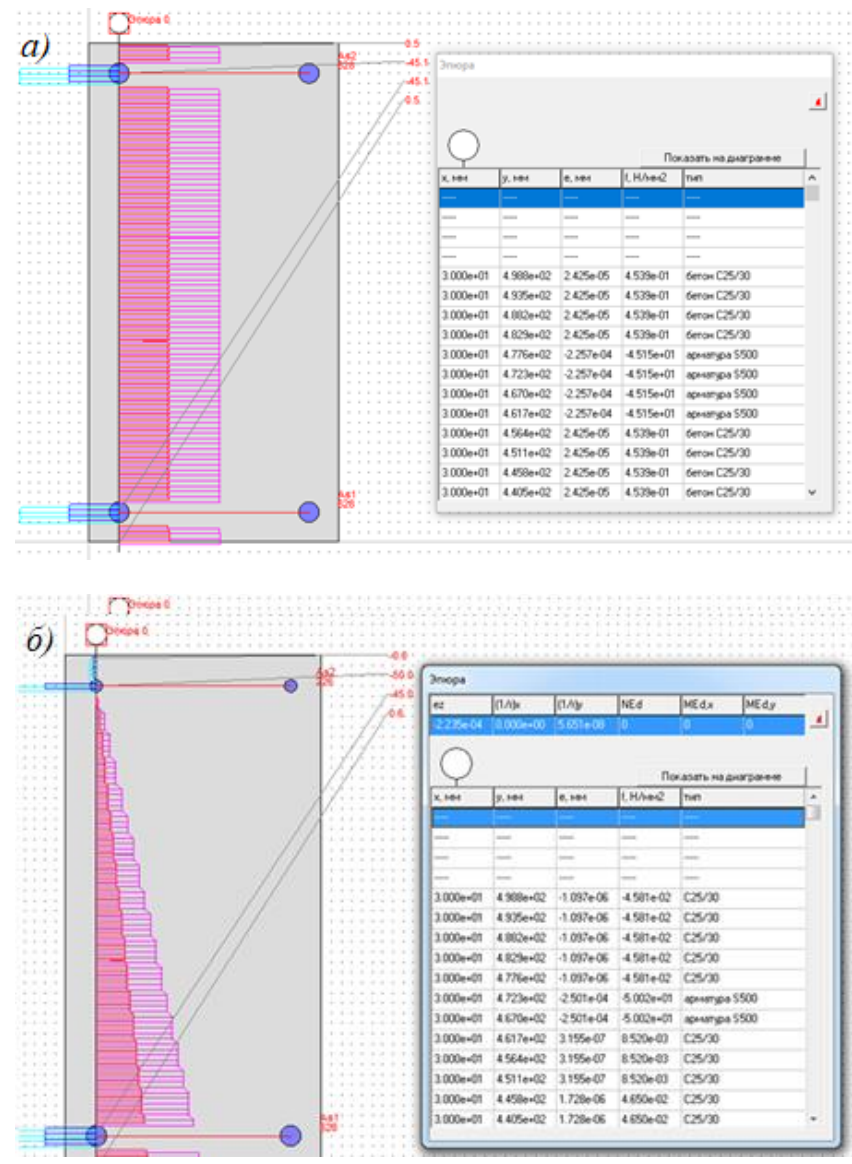

а) симметричное армирование;

б) несимметричное армирование

Рисунок 2 - Результат расчета распределения усадочных деформаций при армировании

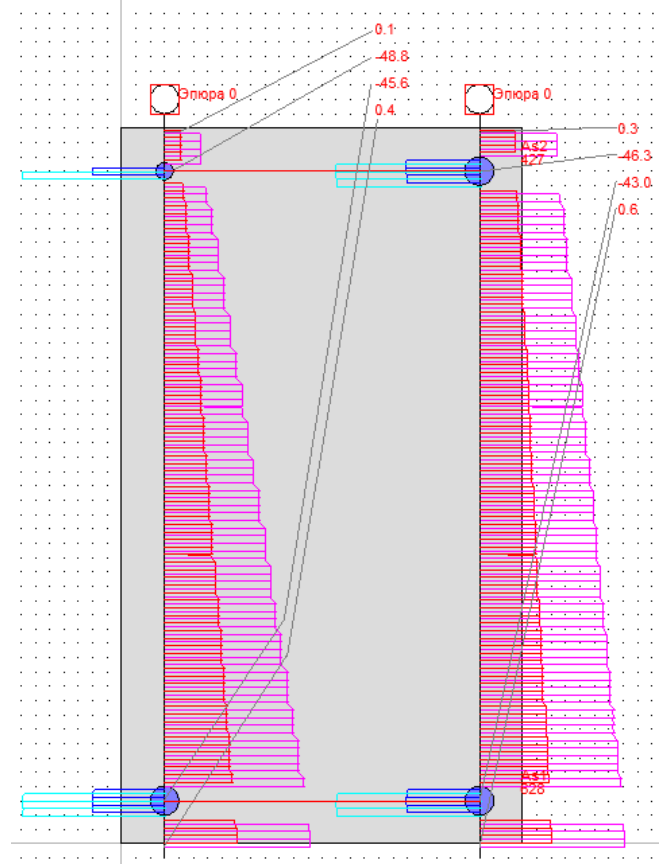

Рисунок 3 - Результат расчета распределения усадочных деформаций при несимметричном армировании в двух плоскостях

В точках контакта арматуры с бетоном сумма относительных деформаций сжатой арматуры и растянутого в результате усадки бетона остается постоянной, равной значению относительной деформация от действия усилия полной усадки бетона $\varepsilon_{c s}(t, t)$.

Наибольшее влияние учет начальных деформаций бетона и арматуры (после перераспределения деформаций усадки бетона) оказывает на оценку трещиностойкости сечения. Так, в рассматриваемом примере момент образования трещин уменьшился с 58,3 кНм до $47,5 \mathrm{kHм}$, а ширина раскрытия трещины при $70 \mathrm{kHм} \mathrm{возросла} \mathrm{с} \mathrm{0,16} \mathrm{мм}$ до 0,21 мм. Количественная оценка влияния учета начальных деформаций усадки зависит от конкретной геометрии сечения, свойств материалов и условий производства железобетонных изделий, но на качественном уровне учет остаточных усадочных деформаций растяжения в бетоне снижает момент трещинообразования и соответственно увеличивает ширину раскрытия трещин.

Для железобетонных элементов с предварительно напряженной арматурой при учете усадки бетона расчет производится в три этапа. На первом этапе определяются параметры напряженно-деформированного состояния нормального сечения от усадки бетона перед отпуском предварительно напряженной арматуры. Для предварительно напряженной арматуры значения относительных деформаций, вычисленных на первом этапе расчета, будут соответствовать потерям предварительного напряжения, происходящим вследствие усадки. На втором этапе вычисляются параметры напряженно-деформированного состояния нормального сечения после обжатия с учетом начальных параметров, полученных на первом этапе расчета. На третьем этапе расчета рассматривается нормальное сечение железобетонного элемента при действии внешней нагрузки.

Алгоритмически определение перераспределения усадочных деформаций по причине восприятия части этих деформаций продольной арматурой аналогично расчету упругого обжатия при моделировании отпуска предварительно-напряженной арматуры. Только в случае действия усадки напряжения растяжения возникают в бетоне.

\section{Учет деформаций ползучести бетона}

Диаграммы деформирования бетона, которые используются в деформационной расчетной модели, представляют собой аппроксимацию результатов экспериментальных исследований и относятся к случаю действия кратковременных нагрузок. На зависимость « $\sigma_{c}-\varepsilon_{c}$ » для бетона из-за ползучести влияет скорость нагружения [5], (рис. 4), градиенты напряжений и десрормаций [6], другие факторы. 


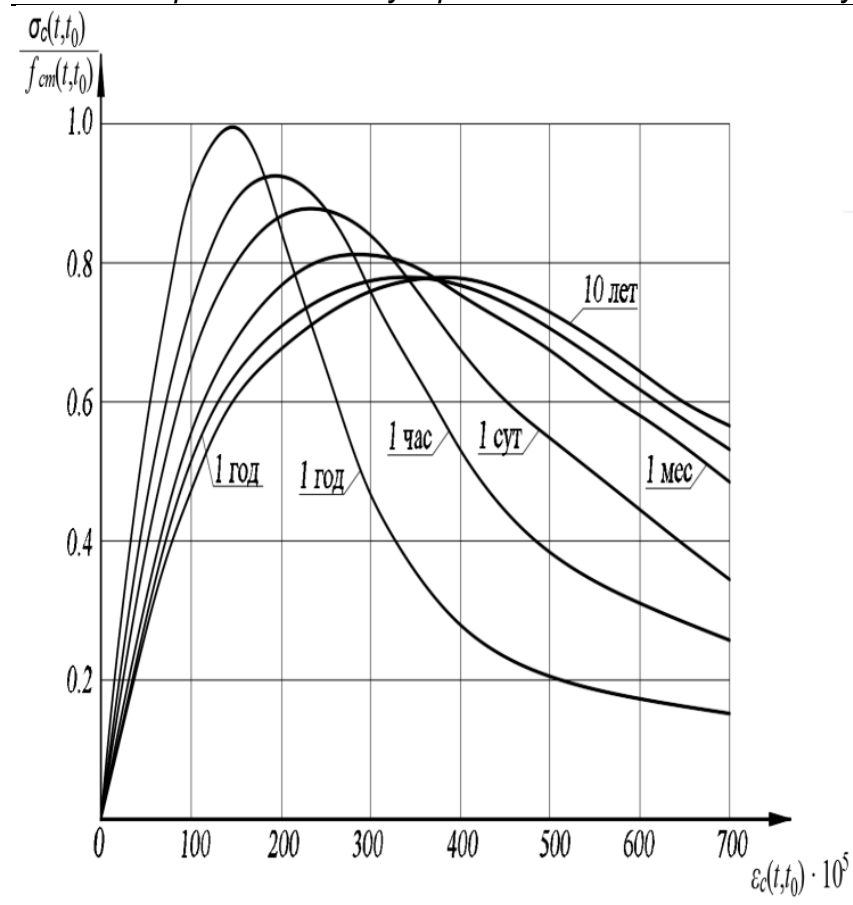

Рисунок 4 - Влияние скорости нагружения на зависимость $\frac{\sigma_{c}\left(t, t_{0}\right)}{f_{c m}\left(t, t_{0}\right)}-\varepsilon_{c}\left(t, t_{0}\right)$

Диаграмму десормирования бетона при кратковременном нагружении $[7,8]$ получают на стандартных призмах, испытываемых с постоянной скоростью роста дефрормаций в 2 \%о в час. При ступенчатом нагружении [9] величина двух первых ступеней составляет 0,05 от ожидаемой предельной нагрузки $N_{u}$, затем величина ступеней увеличивается вдвое. Начиная со ступени $0,85 N_{u}$ все последующие ступени нагружения уменьшают до $0,05 N_{u}$. На каждой ступени нагрузка выдерживается постоянной 4-5 мин.

Для учета деформаций ползучести при расчете напряженнодеформированного состояния железобетонных конструкций на основе деформационной расчетной модели необходимо математическое описание диаграмм деформирования бетона при длительном действии нагрузки. Диаграмму-изохрону можно получить экспериментально [7, 10], если загружать одновременно несколько одинаковых образцов бетона при разных уровнях напряжений в течении одинакового отрезка времени (рис. 5, а) или загружать образцы с постоянной скоростью роста напряжений (рис. 5, б). Если загружение образцов бетона производить с постоянной скоростью роста деформаций, то экспериментально можно получить нисходящую ветвь диаграммы-изохроны (рис. 5, в).
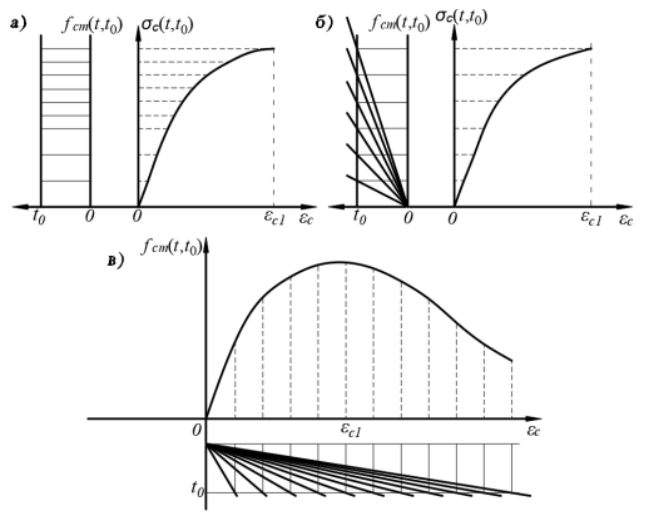

а) ступенчатое напряжение;

б) с постоянной скоростью роста напряжений;

в) с постоянной скоростью роста деформаций

Рисунок 5 - Экспериментальное получение диаграмм-изохрон бетона при длительном нагружении
Экспериментальный путь получения таких диаграмм, который принят при кратковременном нагружении, неприемлем вследствие большого количества факторов, влияющих на ползучесть бетона (каждому режиму нагружения и каждому виду бетона соответствует своя функция ползучести), и требует накопления опытных данных [11]. Поэтому для получения диаграмм деформирования бетона с учетом длительности действия нагрузки используют известные феноменологические теории ползучести, полученные на основе экспериментальных данных при простейших режимах нагружения и последующих обобщений на основе принятых гипотез [12, 13, 14]. Основная гипотеза, используемая для получения зависимости « $\sigma_{c}\left(t, t_{0}\right)-\varepsilon_{c}\left(t, t_{0}\right) »$ для бетона, заключается в следующем: полные деформации бетона складываются из упругих деформаций, возникающих при кратковременном приложения нагрузки, и деформаций ползучести, развивающихся при длительном действии нагрузки.

Известные в настоящее время теории ползучести отличаются, в основном, способом перехода от деформаций ползучести при простейших режимах нагружения к деформациям ползучести при любых режимах нагружения. По виду зависимостей как между напряжениями и упругими деформациями, так и между напряжениями и деформациями ползучести различают линейную и нелинейную теории ползучести. Область линейной зависимости, как правило, ограничивается напряжениями в бетоне $\sigma_{c} \leq(0,4 \ldots 0,5) f_{c m}\left(t_{0}\right)$. В СП 5.03.01-2020 «Бетонные и железобетонные конструкции» область линейной зависимости ограничивается $\sigma_{c} \leq 0,4 f_{c m}\left(t_{0}\right)$. Коэффициент ползучести бетона (соотношение деформаций ползучести и упругих десормаций при одной и той же величине приложенного напряжения в этом случае определяют по формуле

$$
\varphi\left(t, t_{\mathrm{o}}\right)=\varphi_{b c}\left(t, t_{\mathrm{o}}\right)+\varphi_{d c}\left(t, t_{\mathrm{o}}\right),
$$

где $\varphi_{b c}\left(t, t_{\mathrm{o}}\right)$ - базовый коэффициент ползучести;

$\varphi_{d c}\left(t, t_{\mathrm{o}}\right)$ - коэффициент ползучести высыхания;

$t$ - возраст бетона в рассматриваемый момент времени, сут.;

$t_{\text {о }}$ - модифицированный, в зависимости от температуры среды и класса прочности цемента возраст бетона в момент нагружения, сут.

В случае высоких уровней сжимающих напряжений в интервале $0,4 f_{c m}\left(t_{0}\right)<\sigma_{c}<0,6 f_{c m}\left(t_{0}\right)$ определяют модифицированный коэффициент нелинейной ползучести $\varphi_{\sigma}\left(t, t_{0}\right)$ по формуле

$$
\varphi_{\sigma}\left(t, t_{\mathrm{o}}\right)=\varphi\left(t, t_{\mathrm{o}}\right) \exp \left[1,5 \cdot\left(k_{\sigma}-0,4\right)\right]
$$

где $0,4<\mathrm{k}_{\sigma}=\left|\sigma_{c}\right| / f_{c m}\left(t_{0}\right)<0,6$ - коэфффициент, учитывающий уровень нагружения за пределами области линейной зависимости.

Согласно [4] для расчета деформаций железобетонных элементов при длительном действии нагрузки допускается использование табличных предельных значений коэффициента ползучести $\varphi\left(50, t_{0}\right)$, рассчитанных для возраста бетона $t=50$ лет. Могут быть построены номограммы для вычисления предельных значений коэфффициента ползучести [15]. При напряжениях в бетоне $\sigma_{c}>0,4 f_{c m}\left(t_{0}\right)$ выполняют модификацию предельного значения коэффициента ползучести $\varphi\left(50, t_{0}\right)$ с учетом влияния нелинейной ползучести. Предельное значение модифицированного коэффициента нелинейной ползучести в зависимости от сжимающих напряжений $\sigma_{c}\left(t_{0}\right)$ и средней прочности бетона $f_{c m}\left(t_{0}\right)$ в момент времени $t_{0}$ вычисляется по формуле

$$
\varphi_{w}\left(50, t_{0}\right)=\varphi\left(50, t_{0}\right) \cdot \exp \left[1,5 \cdot\left(\frac{\sigma_{c}}{f_{c m}\left(t_{0}\right)}-0,40\right)\right]
$$

Кроме того, согласно [4] относительные деформации ползучести бетона $\varepsilon_{c c}\left(t, t_{0}\right)$ с начальным модулем упругости $E_{c}=1,05 E_{c m}$ железобетонных элементов в момент времени $t$ при постоянных напряжениях $\sigma_{c}$, приложенных в возрасте бетона $t_{0}$, определяются по формуле

$$
\varepsilon_{c c}\left(t, t_{0}\right)=\varphi\left(t, t_{0}\right) \cdot \frac{\sigma_{c}}{E_{c}} .
$$


Вестник Брестского государственного технического университета. 2021

Значения эфффективного модуля деформаций бетона $E_{c, \text { eff }}\left(t, t_{0}\right)$ с учетом длительного действия нагрузки в момент времени $t$ при действии напряжения $\sigma_{c} \leq 0,4 f_{c m}\left(t_{0}\right)$ могут быть вычислены по формуле

$$
E_{c, e f f}\left(t, t_{0}\right)=E_{c m} /\left[1+\varphi\left(t, t_{0}\right)\right]
$$

При напряжениях в бетоне $\sigma_{c}>0,4 f_{c m}\left(t_{0}\right)$ в формуле (9) применяют модифицированный коэффициент нелинейной ползучести $\varphi_{\sigma}\left(t, t_{0}\right)$ или предельное значение модифицированного коэффициента нелинейной ползучести $\varphi_{w}\left(50, t_{0}\right)$.

Полученные по формуле (11) значения эфффективного модуля десормаций бетона при разных уровнях напряжения в момент времени $t$ аппроксимируются кривой, которая будет являться диаграммой-изохроной в заданный момент времени. Кроме того, диаграмму-изохрону можно получить, суммируя относительные деформации ползучести бетона, вычисленные по формуле (11), с упругими относительными деформациями бетона при разных уровнях напряжения в момент времени $t$. Все точки диаграммы-изохроны бетона при нарастании длительной нагрузки для разных уровней напряжений достигают своих значений за одинаковый промежуток времени. Полученные таким образом диаграммы десормирования бетона, учитывающие его ползучесть под нагрузкой, применяют в расчете деформаций железобетонных элементов при длительном действии нагрузки.

Получение диаграммы-изохроны деформирования при моделировании длительного действия нагрузки реализовано в программном комплексе Бета v6.0. Сравнение результатов расчета при кратковременном и длительном с учетом полученной диаграммы-изохронь действии нагрузки построенной от средних значений призменной прочности бетона $f_{c m}$, приводится на рисунке 6 .
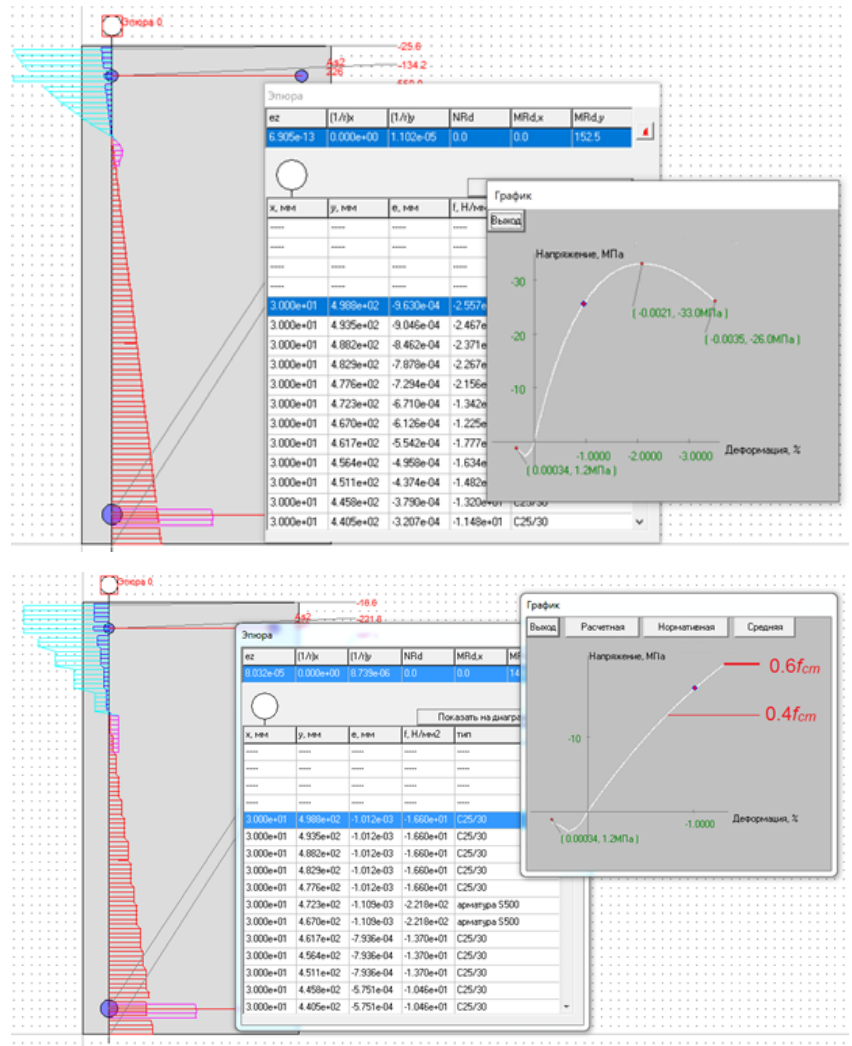

а) при кратковременном действии нагрузки; б) при длительном действии нагрузки с учетом моделирования ползучести

Рисунок 6 - Результаты расчета

В примере изгибаемого железобетонного элемента с поперечным сечением 500×250 мм из обычного бетона класса С25/30 с несимметричным армированием четырьмя стержнями $\varnothing 20(\varnothing 12)$ мм класса
S500 получаем уменьшение расчетного изгибающего момента образования трещин $M_{c r}$ с 58,3 кНм до 53,2 кНм, увеличение расчетной кривизны в рассматриваемом поперечном сечении элемента. Расчет прогиба рассматриваемого изгибаемого элемента пролетом 6 м равномерно распределенной нагрузки при $\gamma_{F}=1$, эквивалентной действию изгибающего момента 70 кНм показывает, что величина прогиба для случая кратковременной нагрузки составляет 18,1 мм, с учетом деформаций ползучести по выше приведенной методике 20,1 мм, а с учетом совместного влияния модели усадки и ползучести 22,2 мм. Соответственно ширина раскрытия трещин при заданном изгибающем моменте без учета усадки и ползучести составляет 0,16 мм, с учетом ползучести 0,17 мм, с учетом совместного влияния деформаций ползучести и усадки 0,21 мм.

\section{Заключение}

Разработана методика учета деформаций усадки и ползучести бетона на основе деформационной расчетной модели для вычисления параметров трещинообразования и деформаций железобетонных элементов при произвольной форме и компоновке поперечного сечения, любом расположении арматуры в пределах сечения.

Совместный учет моделей усадки и ползучести дает суммарный эффрект, уменьшая, по сравнению с кратковременным нагружением, оценку возникающих в железобетонном элементе усилий образования трещин, увеличивая ширину их раскрытия и деформации.

\section{Список цитированных источников}

1. Лившиц, Я. Д. Расчет железобетонных конструкций с учетом влияния усадки и ползучести бетона / Я. Д. Лившиц. - Киев: Вища школа, 1976.

2. Сидоров, А. В. О закономерностях подобия ползучести и усадки железобетонных элементов / А. В. Сидоров // Изв. вузов. Сер.. 1988. - № 1: Строительство и архитектура. - С. 5-10.

3. Рекомендации по учету ползучести и усадки бетона при расчете бетонных н железобетонных конструкций // НИИЖБ Госстроя СССР. - Москва : Стройиздат, 1988. - 121 с.

4. Бетонные и железобетонные конструкции: СП 5.03.01-2020 // Минск: Министерства архитектуры и строительства Республики Беларусь, 2020. - 236 с.

5. Карпенко, Н. И. Диаграммы деформирования бетона, их трансформации в зависимости от различных факторов и использование в расчетах конструкций / Н. И. Карпенко, Т. А. Мухамедиев, А. Н. Петров // Материалы конференций и совещаний по гидротехнике: Предельные состояния бетонных и железобетонных конструкций энергетических сооружений. - Л. : Энергоатомиздат, 1987.

6. Чайка, В. П. Характеристики диаграмм неоднородного сжатия бетона / В. П. Чайка // Бетон и железобетон. - 1994. - № 1. - С. 18-23.

7. Карпенко, Н. И. Исходные и трансформированные диаграммы деформирования бетона и арматуры / Н. И. Карпенко, Т. А. Мухамедиев, А. Н. Петров // Сб. Напряженно-деформированное состояние бетонных и железобетонных конструкций. - М.: НИИЖБ, 1986.

8. Мухамедиев, Т. А. К нормированию диаграммы деформирования бетона при осевом сжатии / Т. А. Мухамедиев // Сб. Инженерные проблемы современного железобетона. - Иваново: ИИСИ, 1995. C. $235-241$.

9. Методические рекомендации по определению основных механических характеристик бетонов при кратковременном и длительном нагружении. - М. : НИИЖБ, 1984. -52 с.

10. Методические рекомендации по исследованию ползучести и усадки бетона. - М. : НИИЖБ, 1975. - 118 с.

11. Несветаев, Г. В. Модель для оценки влияния рецептурных факторов на коэффициент ползучести бетона [Электронный ресурс] / Г. В. Несветаев, С. В. Халезин // Науковедение. - 2017. - Том 9, №1. - Режим доступа: http://naukovedenie.ru/PDF/04TVN117.pdf.

12. Бондаренко, В. М. Инженерные методы нелинейной теории железобетона / В. М. Бондаренко, С. В. Бондаренко. - М. : Стройиздат, 1982. - 287 с.

13. Прокопович, И. Е. Влияние длительных процессов на напряженное и деформированное состояние сооружений / И. Е. Прокопович. - М.: Стройиздат, 1963. -260 с. 
Вестник Брестского государственного технического университета. 2021

14. Прокопович, И. Е. Прикладная теория ползучести / И. Е. Прокопович, В. А. Зедгенидзе. - М.: Стройиздат, 1980.

15. Глухов, Д. О. Мяглие вычисления для организации компьютерного представления омограмм на примере вычисления предельного коэффиициента позучести / Д. О. Глухов, Т. М. Глухова, С. П. Кундас // Вестник Полоцкого государственного университета. Серия С. -2010 - С. 2-6.

\section{References}

1. Livshic, YA. D. Raschet zhelezobetonnyh konstrukcij s uchetom vliyaniya usadki i polzuchesti betona / YA. D. Livshic. - Kiev: Vishcha shkola, 1976

2. Sidorov, A. V. O zakonomernostyah podobiya polzuchesti i usadki zhelezobetonnyh elementov / A. V. Sidorov // Izv. vuzov. Ser.. 1988. - № 1: Stroitel'stvo i arhitektura. - S. 5-10.

3. Rekomendacii po uchetu polzuchesti i usadki betona pri raschete betonnyh n zhelezobetonnyh konstrukcij // NIIZHB Gosstroya SSSR. Moskva : Strojizdat, 1988. - $121 \mathrm{~s}$.

4. Betonnye i zhelezobetonnye konstrukcii: SP 5.03.01-2020 // Minsk: Ministerstva arhitektury i stroitel'stva Respubliki Belarus', 2020. - $236 \mathrm{~s}$.

5. Karpenko, N. I. Diagrammy deformirovaniya betona, in transformacii $v$ zavisimosti ot razlichnyh faktorov $i$ ispol'zovanie $v$ raschetah konstrukcij / N. I. Karpenko, T. A. Muhamediev, A. N. Petrov // Materialy konferencij i soveshchanij po gidrotekhnike: Predel'nye sostoyaniya betonnyh i zhelezobetonnyh konstrukcij energeticheskih sooruzhenij. L. : Energoatomizdat, 1987.

6. CHajka, V. P. Harakteristiki diagramm neodnorodnogo szhatiya betona / V. P. CHajka // Beton i zhelezobeton. - 1994. - № 1. S. $18-23$.
7. Karpenko, N. I. Iskhodnye i transformirovannye diagrammy deformirovaniya betona i armatury / N. I. Karpenko, T. A. Muhamediev, A. N. Petrov // Sb. Napryazhenno-deformirovannoe sostoyanie betonnyh i zhelezobetonnyh konstrukcij. - M.: NIIZHB, 1986.

8. Muhamediev, T. A. K normirovaniyu diagrammy deformirovaniya betona pri osevom szhatii / T. A. Muhamediev // Sb. Inzhenernye problemy sovremennogo zhelezobetona. - Ivanovo: IISI, 1995. S. 235-241.

9. Metodicheskie rekomendacii po opredeleniyu osnovnyh mekhanicheskih harakteristik betonov pri kratkovremennom i dlitel'nom nagruzhenii. - M. : NIIZHB, 1984. $-52 \mathrm{~s}$

10. Metodicheskie rekomendacii po issledovaniyu polzuchesti i usadk betona. - M. : NIIZHB, 1975. - $118 \mathrm{~s}$

11. Nesvetaev, G. V. Model' dlya ocenki vliyaniya recepturnyh faktorov na koefficient polzuchesti betona [Elektronnyj resurs] / G. V. Nesvetaev, S. V. Halezin // Naukovedenie. - 2017. - Tom 9, №1. - Rezhim dostupa: http://naukovedenie.ru/PDF/04TVN117.pdf.

12. Bondarenko, V. M. Inzhenernye metody nelinejnoj teorii zhelezobetona / V. M. Bondarenko, S. V. Bondarenko. - M. : Strojizdat, 1982. - $287 \mathrm{~s}$.

13. Prokopovich, I. E. Vliyanie dlitel'nyh processov na napryazhennoe i deformirovannoe sostoyanie sooruzhenij / I. E. Prokopovich. - M.: Strojizdat, 1963. $-260 \mathrm{~s}$.

14. Prokopovich, I. E. Prikladnaya teoriya polzuchesti / I. E. Prokopovich, V. A. Zedgenidze. - M.: Strojizdat, 1980.

15. Gluhov, D. O. Myaglie vychisleniya dlya organizacii komp'yuternogo predstavleniya omogramm na primere vychisleniya predel'nogo koefficienta pozuchesti / D. O. Gluhov, T. M. Gluhova, S. P. Kundas // Vestnik Polockogo gosudarstvennogo universiteta. Seriya S. - 2010. S. 2-6.

Материал поступил в редакцию 24.05.2021 